\title{
Indian public health standards for Ayurveda, Yoga and Naturopathy, Unani, Siddha and Homoeopathy facilities: An assessment
}

\section{Janmejaya Samal \\ Padmashree School of Public Health, Bengaluru, Karnataka, India}

Address for the Correspondence:

Dr. Janmejaya Samal, Padmashree School of Public Health, Bengaluru - 560 072, Karnataka, India. E-mail: janmejaya_samal@ yahoo.com, jaytheworld@ gmail.com

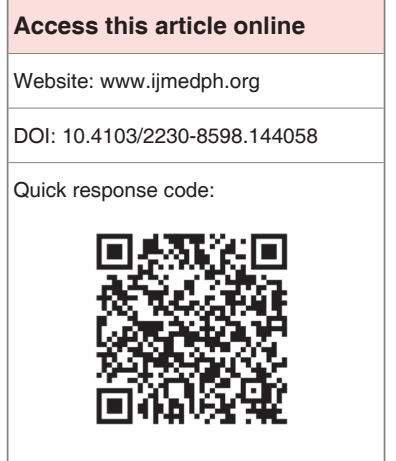

Background: Indian Public Health Standards (IPHS) are the prescribed quality norms for health care services in India. For the first time this set of standards was introduced with the initiation of National Rural Health Mission in India. The first set of standards was released in 2007 and the second revised set was released in 2012. Among various services Ayurveda, Yoga and Naturopathy, Unani, Siddha, and Homeopathy (AYUSH) is one of the components and certain standards have also been prescribed for AYUSH facilities in concerned health institutions. Materials and Methods: A review was made based on the prescribed IPHS documents obtained from the web portal of Directorate of Health Services, Ministry of Health and Family Welfare, Government of India, New Delhi. Results and Discussion: Human resources and drugs have been dealt in detail in all the health institutions. Treatment of common ailments with AYUSH drugs as per the local need, training of health worker in AYUSH drugs and promotion of medicinal plants are some of the services prescribed at sub center level. Description regarding the drugs is only found in primary and Community Health Centers. Manpower under AYUSH has been categorized under essential services in all the institutions except Primary Health Center in which the same has been categorized in desirable services. Conclusion: Mainstreaming of AYUSH and prescribing IPHS standards are some of the important initiatives under NRHM as a substantial portion of rural India is still dependent upon the AYUSH systems of medicine as a way of availing health care services. However, a more detailed prescription for this sector would always be of significance for the society and the sector itself.

Key words: Ayurveda, yoga and Naturopathy, unani, siddha, and homeopathy, facilities, Indian public health standards

\section{INTRODUCTION}

Standards are a mean of describing level of quality that the health care organizations are expected to meet or aspire to achieve. For the first time under National Rural Health Mission (NRHM), an effort has been made to develop Indian Public Health Standards (IPHS) for a vast network of peripheral public health institutions in the country and the first set of standards was released in early 2007 to provide optimal specialized care to the community and achieve and maintain an acceptable standard of quality of care. The norms are applicable to all health care institutions starting from the sub center up to the level of district hospitals (DHs). These standards are prescribed for all functionalities of an institution such as infrastructure, manpower, drugs and equipments, laboratory services, operation theatre, bio-waste management, capacity building, quality control and quality assurance, including statutory compliance and citizen charter. Among various services Ayurveda, Yoga and Naturopathy, Unani, Siddha, and Homeopathy (AYUSH) is one of the components. These are the six indigenous systems of medicine practiced in India. These systems are incorporated into mainstream health system in the country with the inception of NRHM. This innovative concept is termed as "mainstreaming of AYUSH and revitalization of local health traditions". This convergence has been envisaged with an objective of providing choice of treatment system to the patients, strengthen facility functionally, and strengthen implementation of national health programs. ${ }^{[1,2]}$ Precisely the concept of mainstreaming of AYUSH was an idea in the IX ${ }^{\text {th }}$-year plan before it was actually implemented in the country by NRHM in 2005. ${ }^{[3]}$ By this AYUSH doctors are co-located in various health facilities such as Primary Health Center (PHC), Community Health Center (CHC), sub district hospital (SDH), and DH. AYUSH facilities had been created in $468 \mathrm{DHs}, 2483 \mathrm{CHCs}$ and 8520 PHCs as on March 
31, 2012. About 76.3\% DHs, 51.6\% CHCs and 35.7\% PHCs had been co-located with AYUSH facilities by this time. As on March 31, 2012, there were 10439 AYUSH doctors and 4146 paramedical staffs serving in India. A maximum of 1386 doctors have been appointed in the state of Bihar, whereas Odisha and Rajasthan have 1237 and 1013 AYUSH doctors appointed respectively. Delhi and Jharkhand are the only two states where AYUSH doctors have not been appointed. In case of paramedical staffs Andhra pradesh is the state where a maximum of 1500 number of AYUSH paramedical staffs have been appointed.

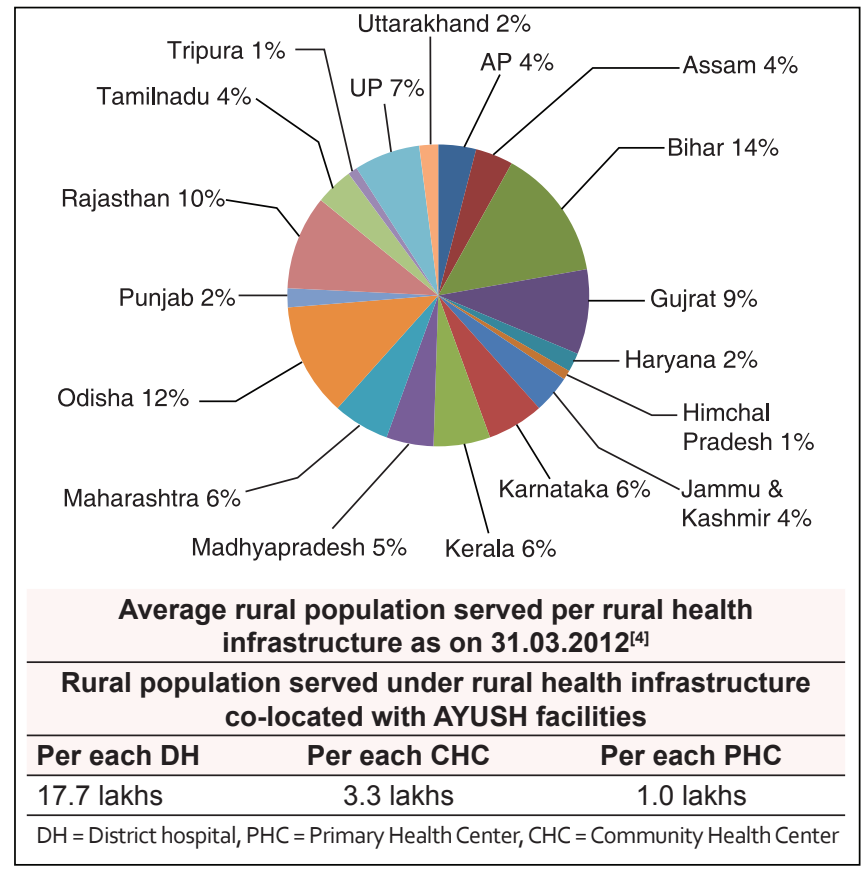

Figure 1: State wise distribution of Ayurveda, Yoga and Naturopathy, Unani, Siddha, and Homeopathy doctors appointed on contractual basis in Primary Health Centers under National Rural Health Mission till March 31, 2012 ("Source - Department of AYUSH, MOHFW, Government of India ${ }^{[4]}$ )
AYUSH paramedical staffs have not been appointed in many states like Arunachal Pradesh, Assam, Bihar, Chhattisgarh, Delhi, Gujarat, Jharkhand, Meghalaya, Mizoram, Nagaland, Orissa, Uttar Pradesh, D and N Haveli and Daman and Diu [Figures 1 and 2]. ${ }^{[4]}$ Similarly about 17.7 lakhs of rural population were being served by each DHs, 3.3 lakhs of rural population were being served by each CHCs and 1.0 lakhs of rural population were being served by each PHCs in various states/Union Territories wherever the corresponding facilities existed [Tables 1 and 2]. ${ }^{[4]}$

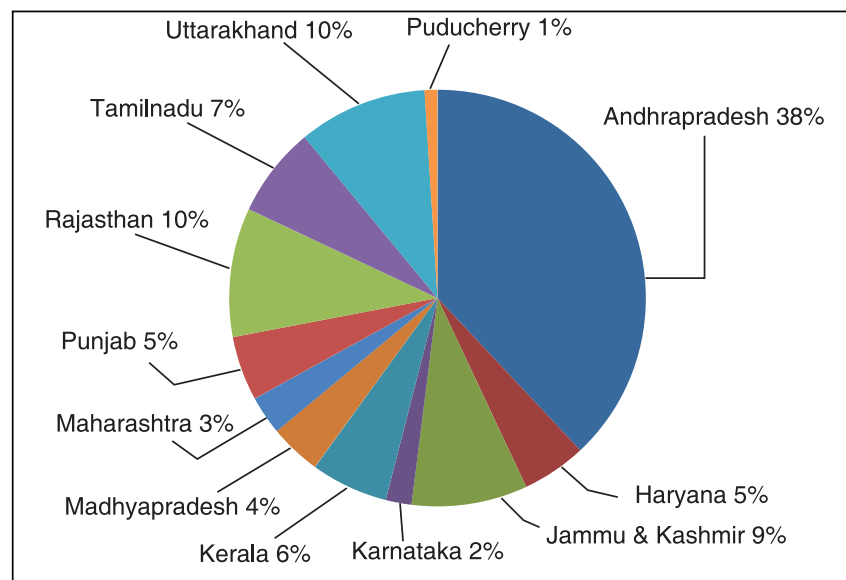

National level contractual appointments under AYUSH as on 31.03.2012 $2^{[4]}$

Number of contractual appointments under AYUSH

Percent distribution of contractual appointments under AYUSH

\begin{tabular}{|lccc|}
\hline Doctors & Paramedical staff & Doctors & Paramedical staff \\
\hline 10,439 & 4146 & $100.0 \%$ & $100.0 \%$ \\
\hline
\end{tabular}

Figure 2: State-wise distribution of Ayurveda, Yoga and Naturopathy, Unani, Siddha, and Homeopathy Paramedics appointed on contractual basis in Primary Health Centers under National Rural Health Mission till March 31, 2012 ("Source - Department of AYUSH, MOHFW, Government of India ${ }^{[4]}$ )

Table 1: AYUSH workforce as per IPHS guidelines ${ }^{[6,7,9-11]}$

\begin{tabular}{llllll}
\hline Personnel & Essential & Desirable & Essential & Desirable & Qualification \\
\hline
\end{tabular}

Sub center

No workforce has been suggested

\begin{tabular}{|c|c|c|c|c|c|}
\hline \multicolumn{6}{|c|}{ PHC } \\
\hline \multicolumn{3}{|l|}{ Type A (<20 deliveries per month) } & \multicolumn{3}{|c|}{ Type B (>20 deliveries per month) } \\
\hline Medical officer (AYUSH) & - & $1^{*}$ & - & $1^{*}$ & \multirow[t]{2}{*}{ Graduate in AYUSH } \\
\hline Pharmacist (AYUSH) & - & 1 & - & 1 & \\
\hline \multicolumn{6}{|c|}{$\mathrm{CHC}$} \\
\hline Graduate medical officer (AYUSH) & 1 & - & \multicolumn{2}{|c|}{ No categorization } & \multirow[t]{2}{*}{ Graduate in $\mathrm{AYUSH}$} \\
\hline Pharmacist (AYUSH) & 1 & - & No cate & zation & \\
\hline \multicolumn{6}{|c|}{ SDH } \\
\hline 31-50 bedded SDH & & & \multicolumn{3}{|c|}{ 51-100 bedded SDH } \\
\hline AYUSH physician & $1^{\#}$ & - & 1 & - & \\
\hline \multicolumn{6}{|c|}{$\mathrm{DH}^{\neq}$} \\
\hline & 100 beds & 200 beds & 300 beds & 400 beds & 500 beds \\
\hline AYUSH physician $^{\vee}$ & 1 & 1 & 1 & 2 & 2 \\
\hline AYUSH pharmacist & 1 & 1 & 1 & 1 & 1 \\
\hline
\end{tabular}

*To provide choices to people wherever an AYUSH facility is not available in the near vicinity, "Provided there is no AYUSH hospital/dispensary in the district head quarter, One from AYUSH Safai Karamchari is to be outsourced, VIf more than one AYUSH doctors are available; at least one doctor should have a recognized PG qualification in relevant system under AYUSH, ${ }^{7}$ AYUSH services have proposed in the essential category at DH, IPHS = Indian Public Health Standards, SDH = Sub district hospital, DH = District hospital, $\mathrm{PHC}=$ Primarv Health Center, $\mathrm{CHC}=$ Communitv Health Center 


\begin{tabular}{|c|c|c|c|c|}
\hline $\begin{array}{l}\text { Name of the } \\
\text { institution }\end{array}$ & Ayurveda & Unani & Siddha & Homoeopathy \\
\hline \multicolumn{5}{|l|}{ Sub center } \\
\hline $\mathrm{PHC}$ & 100 & 113 & $37+1^{*}$ & 481 \\
\hline $\mathrm{CHC}$ & 125 & 116 & $93+1^{*}$ & 483 \\
\hline $\mathrm{SDH}$ & - & - & - & - \\
\hline $\mathrm{DH}$ & - & - & - & - \\
\hline
\end{tabular}

*One patient and proprietary drug named 777 oil for psoriasis has been proposed, $\mathrm{SDH}=$ Sub district hospital, $\mathrm{PHC}=$ Primary Health Center, $\mathrm{CHC}=$ Community Health Center, $\mathrm{DH}=$ District hospital

\section{MATERIALS AND METHODS}

This review is based on the prescribed documents of IPHS obtained from the Directorate of Health Services, Ministry of Health and Family Welfare, Government of India, New Delhi. Each document from sub center to $\mathrm{DH}$ has been reviewed separately. In the process of review attempt has been made to look into different aspects such as manpower, drugs and specialized services under AYUSH.

\section{RESULTS AND DISCUSSION}

In this section, prescribed norms of IPHS for AYUSH facilities at different level of health care have been discussed in separate headings. The discussion begins with sub center, which is the peripheral most health care institution in the hierarchy and ends with $\mathrm{DH}$, which is the highest level of health care institution in a district.

\section{Sub center}

In Indian public health system a sub center forms the first point of contact between the community and health care institution. This is the most peripheral institution in our country. As per the population norms a sub center is established for every 5000 population in plain area and for 3000 population in hilly area. The purpose of sub center is largely preventive and promotive, but it also provides a basic level of curative care. Providing AYUSH services at the grass root level is of paramount importance as in many parts of rural India people still believe in their traditional system of medicine. The traditional system of medicine is one of the most acceptable, affordable and accessible health services for the remote and rural population. On a Knowledge, Attitude and Practice survey by Dr. Elizabeth Negi in Mawlam village, Meghalaya it was found that people spend 60 rupees annually for consulting a traditional therapist whereas they spend 2600 rupees for an allopath. ${ }^{[5]}$ This indicates the real need of traditional health care services in rural areas which should undoubtedly be provided from the governmental end and simultaneously the same need to be standardized. With this background certain prescribed norms have been put forth in the IPHS document for sub center for AYUSH services. Important services prescribed in the IPHS guidelines for AYUSH at a sub center level are as follows;
- Treatment of minor ailments as per AYUSH as needed at the local level.

- Locally available medicinal herbs/plants should be grown around the sub center as per the guidelines of Department of AYUSH (desirable).

- $\quad$ Provide treatment as per AYUSH as per the local need. Auxiliary nurse midwiferys and multipurpose worker $(\mathrm{M})$ be trained in basic AYUSH drugs (desirable). ${ }^{[]}$

\section{Primary Health Center}

A PHC is the second line of health institution after a sub center in the hierarchy of health care institutions providing public health services in India. In the sixth 5 year plan a PHC was proposed to cater the health needs of 30,000 and 20,000 populations in plain and hilly and tribal area, respectively. The nomenclature of a PHC varies from State to State that include a block level PHCs (located at block HQ and covering about 100,000 population and with varying number of indoor beds) and additional PHCs/new PHCs covering a population of 20,000-30,000 etc. Regarding the block level PHCs it is expected that they are ultimately going to be upgraded as $\mathrm{CHC}$ with 30 beds for providing specialized services. Based on the monthly delivery load PHCs are categorized into Type A with a delivery load of $<20$ and Type B if the same is more than 20. Integration of AYUSH services into the primary health care was a concept of IXth/ninth 5 year plan before it was actually implemented in the country in 2005 under NRHM. NRHM brought this concept in an innovative way called as "mainstreaming of AYUSH and revitalization of local health traditions." This integration has been envisaged with the objective of providing choice of treatment system to the patients, strengthen facility functionally and strengthen implementation of national health programs. ${ }^{[2,6]}$ Most of the guidelines prescribed in the IPHS are based on the mainstreaming of AYUSH. These are categorized as desirable services and are as follows: ${ }^{[7]}$

- Provision of one AYUSH doctor and one AYUSH Pharmacist has been made at PHC to provide choices to the people wherever an AYUSH public facility is not available in the near vicinity. The co-location of AYUSH doctors have happened to a large extent throughout the country which is not the same with AYUSH pharmacist.

- The AYUSH doctor at PHC shall attend patients for system specific AYUSH based preventive, promotive and curative health care and take up public health education activities including awareness generation about the uses of medicinal plants and local health practices. This is really a critical situation in many different states. The AYUSH doctors are not able to meet this as envisaged by NRHM owing to several reasons. The reason might be nonavailability of Allopathic counterpart or heavy patient load which compels them to provide allopathic services and other emergency services.

- The signboard of the PHC should mention AYUSH facilities. 
- AYUSH doctor should support implementation of national health programs after requisite training if required. Training and orientation of AYUSH doctor is one of the important agenda of NRHM. This is required to a great extent because of the Term of References (TORs)/job responsibilities of an AYUSH doctor. There are some job responsibilities mentioned under the TOR, which are beyond the scope of an AYUSH doctor as per his/her educational training and exposure. Let us pick up some responsibilities mentioned in the TOR of AYUSH doctors in Orissa; conducting minor surgery, abscess surgery, conducting normal delivery and insertion of intra uterine contraceptive device are beyond the scope of an AYUSH doctor as per one's training and exposure. Similarly, planning and implementation of national disease control programs, national health programs such as immunization program, Reproductive and Child Health program, supervision of Village Health Nutrition Day and Pustikar Divas, implementation of Integrated Management of Neonatal and Childhood Illnesses requires lot of training and orientation of AYUSH doctors. The importance of training is known very well still timely training is not being conducted in many parts of the country. ${ }^{[8]}$

- Locally available medicinal herbs/plants should be grown around the PHC.

- Necessary infrastructure such as consultation room for AYUSH doctor and dispensing room for AYUSH pharmacist should be provided separately in PHCs wherever AYUSH facilities exist.

\section{Community Health Center}

The CHCs constitute the secondary level of health care, were designed to provide referral as well as specialist health care to the rural population. Under the mainstreaming of AYUSH and revitalization of local health traditions AYUSH doctors have also been collocated in CHCs. The nomenclature of CHC differs from state to state as the block level PHC sometimes represents the CHC. This includes a block level PHCs (located at block HQ and covering about 100,000 populations and with varying number of indoor beds). The IPHS guideline mentions about AYUSH services under the heading of service delivery (both outpatient department and inpatient department) in CHCs. ${ }^{[7,9]}$

\section{Sub district hospital}

Subdistrict (subdivisional) hospitals are below the district and above the block level (CHC) hospitals and act as first referral units for the Tehsil/Taluk/block population in which they are geographically located. The IPHS guideline mentions about AYUSH services under the category of essential health services in an SDH. ${ }^{[10]}$

\section{District hospital}

District hospital is an essential component of the district health system and functions as a secondary level of health care, which provides curative, preventive and promotive health care services to the people in the district. The IPHS guideline mentions about
AYUSH services under the category of essential health services in a DH. ${ }^{[1]}$ At both these level secondary care services from different AYUSH systems can be provided if PG AYUSH doctors are appointed at these levels. It is obvious that one system of medicine is not omnipotent to address all the health care needs of the community. There are some diseases that cannot be addressed by modern allopathic approach could be addressed by some of the AYUSH systems. Even if the same is not true an integrative approach to a particular disease can bring better results than monopathy. If we take the example of Ayurveda, it has its own way of approaching a particular disease which is not the case with other system of medicine. The best example could be Panchakarma therapy which could very well be applied to a wide range of health problems such as degenerative changes, and senile disorders. So brining these services into mainstream and standardizing them under IPHS guidelines can be of immense help to the needy community at a large.

\section{CONCLUSION}

Mainstreaming of AYUSH and prescribing IPHS standards are some of the important initiatives under NRHM as a substantial portion of rural India is still dependent upon the AYUSH systems of medicine as a way of availing health care services. However, a more detailed prescription for this sector would always be of significance for the society and the sector itself. One example of Ayurveda can help to understand it better; it has all the parallel clinical specializations in it which can allow the society to have a choice based or a cafeteria approach in accessing clinical services under a single roof. Apart from this it has its own specialized services such as Pancakarma cikitsa (five specialized therapy), ksharasutra cikitsa (medicated alkaline thread used for the treatment of ano-rectal diseases) which could be designed properly. Bringing standards in these services would help in two ways:

a. The diseases, which are difficult to approach in Allopath can be done with AYUSH systems and vice versa;

b. Some diseases could be approached in an integrated manner blending different systems of medicine. These ideas can also be applied in public health program management.

\section{REFERENCES}

1. Ministry of Health and Family Welfare. National Rural Health Mission (2005-2012), Mission Document. New Delhi: Government of India; 2005.

2. Ministry of Health \& Family Welfare. National Rural Health Mission, Framework of Implementation 2005-2012. New Delhi: Government of India; 2005.

3. National Health System Resource Center-National Rural Health Mission, Mainstreaming of AYUSH and Revitalization of Local Health Traditions Under NRHM, An Appraisal of the Annual State Program Implementation Plans 2007-2010 and Mapping of Technical Assistance Needs. New Delhi: Ministry of Health and Family Welfare, Government of India; 2011.

4. Department of AYUSH. Ministry of Health and Family Welfare. New Delhi: Government of India; 2013.

5. Initiatives for promotion of AYUSH intervention in the public health system of the country - A report on stakeholders' workshop on "AYUSH intervention in public health" held on $8^{\text {th }}$ and $9^{\text {th }}$ Feb 2008, at Foundation for revitalization of local health traditions (FRLHT), Bangalore. 
6. Ministry of Health and Family Welfare. Indian Public Health Standards, Revised Guidelines for Sub Center, Directorate General of Health Services. New Delhi: Govt. of India; 2012.

7. Ministry of Health and Family Welfare. Indian Public Health Standards, Revised Guidelines for Primary Health Center, Directorate General of Health Services. New Delhi: Govt. of India; 2012.

8. Samal J. A review on mainstreaming of AYUSH and revitalization of local health traditions under NRHM. J Res Educ Indian Med (Accepted for Publication).

9. Ministry of Health and Family Welfare. Indian Public Health Standards, Revised Guidelines for Community Health Center, Directorate General of Health Services. New Delhi, Govt. of India, 2012.

10. Ministry of Health and Family Welfare. Indian Public Health Standards,
Revised Guidelines for Sub District Hospital, Directorate General of Health Services. New Delhi, Govt. of India; 2012.

11. Ministry of Health and Family Welfare. Indian Public Health Standards, Revised Guidelines for District Hospital, Directorate General of Health Services. New Delhi: Govt. of India; 2012.

How to cite this article: Samal J. Indian public health standards for Ayurveda, Yoga and Naturopathy, Unani, Siddha and Homoeopathy facilities: An assessment. Int J Med Public Health 2014;4:331-5.

Source of Support: Nil, Conflict of Interest: None declared.

Announcement

\section{“QUICK RESPONSE CODE” LINK FOR FULL TEXT ARTICLES}

The journal issue has a unique new feature for reaching to the journal's website without typing a single letter. Each article on its first page has a "Quick Response Code". Using any mobile or other hand-held device with camera and GPRS/other internet source, one can reach to the full text of that particular article on the journal's website. Start a QR-code reading software (see list of free applications from http://tinyurl.com/yzlh2tc) and point the camera to the QR-code printed in the journal. It will automatically take you to the HTML full text of that article. One can also use a desktop or laptop with web camera for similar functionality. See http://tinyurl.com/2bw7fn3 or http://tinyurl.com/3ysr3me for the free applications. 